\title{
A PERCEPÇÃO DE EGRESSOS/AS DO SISTEMA DE COTAS RACIAIS DA UNIVERSIDADE ESTADUAL DE LONDRINA QUANTO ÀS POLÍTICAS DE PERMANÊNCIA
}

\author{
THE PERCEPTION OF THE GRADUATES OD THE SYSTEM OF \\ QUOTAS RACIAL OF THE STATE UNIVERSITY OF LONDRINA \\ ABOUT THE PERMANENCE POLICIES
}
LA PERCEPCIÓN DE LOS GRADUADOS DEL SISTEMA DE CUOTAS RACIALES DE LA UNIVERSIDAD ESTATAL DE LONDRINA RESPECTO A LAS POLÍTICAS DE PERMANENCIA

\author{
JÉSSICA JUSTINO BRANDÃO \\ Margarida De CÁssia CAMPos ${ }^{\text {II }}$ \\ 'Universidade Estadual de Londrina (UEL), Londrina/PR-Brasil \\ "Universidade Estadual de Londrina(UEL), Londrina/PR-Brasil
}

RESUMo O presente artigo teve como objetivo investigar a percepção dos egressos do sistema de cotas da Universidade Estadual de Londrina sobre as políticas de permanência dessa instituição. Na primeira parte, são discutidas as políticas de ações afirmativas no ensino superior no Brasil e na UEL; para tanto, utilizaram-se as obras de: Silva e Pacheco (2012), Silva (2014), Feres Junior et al. (2017) e Souza (2018), entre outros. Na segunda parte, abordam-se as políticas de permanência instituídas no Brasil nas Universidades Federais e Estaduais e, posteriormente, o contexto das políticas de cotas e de permanência na universidade estudada. Por fim, apresentou-se um levantamento realizado por meio de questionário on-line com 200 egressos cotistas raciais da UEL, que se formaram entre 2010 e 2016 . As perguntas investigadas neste artigo dizem respeito especificamente à questão da permanência desses estudantes e perpassaram assuntos como dificuldades enfrentadas, racismo, auxílios estudantis e possíveis sugestões de melhorias das políticas de permanência dessa universidade. Constatou-se que tais políticas são necessárias para que estudantes negros consigam concluir o curso; no entanto, precisam ser ampliadas e, principalmente, mais bem divulgadas, para que atinjam uma quantidade maior de estudantes.

Palavras-chave: Políticas de Permanência; Universidade Estadual de Londrina; EgRESSOS. 
ABSTRacr This article had as objective to investigate the perception of the graduates of the system of quotas of the State University of Londrina about the permanence policies of this educational institution. The first part discusses affirmative action policies in higher education in Brazil and at State University of Londrina; therefore, used the works of Silva e Pacheco (2012), Silva (2014), Feres Junior et al. (2017) e Souza (2018), among others. In the second part, the permanence policies instituted in Brazil in the Federal and State Universities were approached and, later, the context of the quotas and permanence policies of the State University of Londrina. Finally, a survey was conducted through an online questionnaire with 200 racial quota graduates from the State University of Londrina, who graduated between 2010 and 2016. The questions investigated in this article relate specifically to the issue of permanence of these students and covered issues such as difficulties faced, racism, student aids and possible suggestions for improving the permanence policies of this university. It has been found that such policies are necessary for black students to complete the course; however, they need to be expanded and, especially, better publicized by the University to reach more students.

\section{Keywords: Permanence Policies; State University of Londrina; Graduates.}

Resumen Este artículo pretendía investigar la percepción de los graduados del sistema de cuotas de la Universidad Estatal de Londrina sobre las políticas de permanencia de esta institución. En la primera parte, se discuten las políticas de acción afirmativa en la educación superior en Brasil y en la UEL, utilizando las obras de: Silva y Pacheco (2012), Silva (2014), Feres Junior et al. (2017) y Souza (2018), entre otros. En la segunda parte, se abordan las políticas de permanencia instituidas en Brasil en las universidades federales y estatales y, posteriormente, el contexto de las políticas de cuotas y permanencia en la universidad estudiada. Finalmente, se presentó una encuesta realizada a través de un cuestionario en línea con 200 graduados de los titulares de cuotas raciales de la UEL, que se graduaron entre $2010 \mathrm{y}$ 2016. Las preguntas que se investigan en este artículo se refieren específicamente al tema de la permanencia de estos estudiantes y abarcan temas como las dificultades que enfrentan, el racismo, la ayuda estudiantil y las posibles sugerencias para mejorar las políticas de permanencia de esta universidad. Se encontró que tales políticas son necesarias para que los estudiantes negros puedan completar el curso; sin embargo, necesitan ser ampliadas y, sobre todo, mejor publicitadas, para que lleguen a un mayor número de estudiantes.

Palabras clave: Políticas Permanentes; Universidad Estatal de Londrina; GraDUADOS.

\section{INTRODUÇÃo}

A implantação das políticas de ações afirmativas no Brasil, em especial as de reserva de vagas em universidades estaduais e federais, foi um importante passo para a busca de uma verdadeira democratização das Instituições de Ensino Superior (IES) nos últimos anos. No entanto, cabe ressaltar que tais políticas, isoladas, não terão o mesmo resultado de inclusão se não existirem, concomitantemente, políticas de permanência que acolham e acompanhem os estudantes. 
Por essa razão, Cunha (2017) e Gomes (2009) destacam, também, que as políticas de Estado relacionadas à permanência não devem se resumir apenas à distribuição de bolsas; devem, sim, estar presentes em diversas vertentes, como nos apoios pedagógico e psicológico, no incentivo à pesquisa, na busca pela inserção da discussão racial nos currículos de graduação, nas criações de ouvidorias de ação afirmativa, de grupos de discussão na comunidade acadêmica, entre outras ações.

Levando em consideração essas premissas, o presente artigo tem por objetivo investigar a percepção dos egressos do sistema de cotas da Universidade Estadual de Londrina (UEL) sobre as políticas de permanência dessa instituição de ensino.

Na primeira e na segunda partes, foram levantadas informações sobre as políticas de ações afirmativas e de permanência no ensino superior do Brasil. A terceira parte contempla uma investigação acerca da implantação, modificações e ampliações das políticas de permanência nas universidades brasileiras e na Universidade Estadual de Londrina, respectivamente. Na quarta e última parte, buscou-se investigar quais são as concepções dos egressos cotistas raciais da UEL a respeito das políticas de permanência nessa universidade, bem como, possíveis dificuldades encontradas durante a formação deles.

Como procedimentos metodológicos foi feita, inicialmente, uma seleção bibliográfica de obras fundamentais sobre as políticas de ação afirmativa no Brasil e no mundo. Após esse levantamento bibliográfico, as questões do questionário foram elaboradas e enviadas, por e-mail, para todos os estudantes cotistas raciais egressos que se formaram entre os anos de 2010 e 2016 na Universidade Estadual de Londrina (total de 808 egressos). Esse período foi contemplado porque abrange aqueles estudantes que ingressaram a partir do primeiro ano em que o vestibular da UEL destinava vagas a cotistas raciais e sociais (2005). Foram recebidas 200 respostas ao questionário, as quais representam $24,7 \%$ do total dos cotistas raciais que se formaram no período pesquisado. Ressalte-se ainda que, dos 808 e-mails enviados, 39 retornaram por erro ou falha na entrega ao destinatário.

As perguntas investigadas dizem respeito especificamente à questão da permanência desses estudantes na Universidade Estadual de Londrina e a outros temas como racismo, auxílios estudantis e possíveis sugestões de melhorias das políticas de permanência da UEL.

Para a análise das respostas, foi utilizado, em um primeiro momento, o método quantitativo para a sistematização e tabulação por meio de gráficos e quadros. Posteriormente, com os dados organizados, foi realizada uma análise qualitativa das respostas recebidas, para a melhor interpretação dos fenômenos estudados.

\section{AÇões AFIRMATIVAS no EnSino SUPERIOR}

$\mathrm{O}$ atual processo de democratização do ensino superior possui como uma de suas estratégias principais a adoção de políticas de ação afirmativa, com a finalidade de garantir o ingresso de estudantes historicamente desfavorecidos à universidade. Tais políticas têm como objetivo propiciar uma maior representatividade dos negros e dos indígenas em espaços ainda ocupados por uma elite majoritariamente branca (SOUZA, 2018).

As ações afirmativas são conceituadas como: 
Um conjunto de políticas públicas e privadas de caráter compulsório, facultativo ou voluntário, concebidas com vistas ao combate à discriminação racial, de gênero e de origem nacional, bem como para corrigir os efeitos presentes da discriminação praticada no passado, tendo por objetivo a concretização do ideal de efetiva igualdade de acesso a bens fundamentais, como a educação e o emprego (GOMES, 2003, p. 27).

Silva (2009) acredita que os principais objetivos das ações afirmativas são:

[...] corrigir desigualdades no acesso à participação política, educação, saúde, moradia, emprego, justiça, bens culturais; reconhecer e reparar crimes de desumanização e extermínio contra grupos e populações; reconhecer e valorizar a história, cultura e identidade de grupos sociais e étnico-raciais, bem como a importância de sua participação na construção de conhecimentos valiosos para toda humanidade (SILVA, 2009, p. 264).

Implantadas inicialmente na Índia, em 1948, as políticas de ação afirmativa de recorte racial tinham como objetivo a proteção e a promoção dos grupos indianos historicamente discriminados (FERES JÚNIOR; DAFLON, 2015). No entanto, mesmo após muitas décadas da implantação dessas políticas, a incidência de pobreza é maior nos grupos que hoje são, teoricamente, protegidos pela Constituição do que nos demais indianos.

Nos Estados Unidos, as políticas de ações afirmativas surgiram na década de 1960, fruto da intensa manifestação do movimento negro devido à extrema desigualdade racial que aquele país apresentava. Em 1964, o Congresso dos EUA aprovou a legislação sobre a igualdade de direitos e assumiu a responsabilidade na condução do processo que deveria levar à superação das desigualdades raciais (MEDEIROS, 2009). No entanto, com o passar dos anos, as políticas de ação afirmativa racial nos Estados Unidos sofreram pressões e foram refutadas quanto à sua constitucionalidade perante a $14^{\mathrm{a}}$ Emenda, ou seja, a questão da "proteção igual" na lei a todos os cidadãos nascidos naquele país (LEMPERT, 2015).

O caso Bakke versus Universidade da Califórnia, em 1978, foi um marco na posição do Supremo Tribunal dos Estados Unidos em relação às ações afirmativas de recorte racial. Nesse caso, o juiz Powell definiu que as metas de admissão de minorias seriam inconstitucionais se fossem cotas inflexíveis; mas que, caso não houvesse uma fixação de quantidade de estudante, a promoção da diversidade racial nas universidades era válida. Nos anos seguintes, a constitucionalidade das ações afirmativas foi revista por diversas vezes na Suprema Corte daquele país, estabelecendo, em sua grande maioria, a importância de uma diversidade educacional que não tivesse um número fixo de reservas de vagas (KENNEDY, 2013).

Outros países que possuem políticas de ação afirmativa raciais que, direta ou indiretamente, atingem a população negra por meio desse tipo de ação são França, África do Sul e Brasil.

No Brasil, a discriminação racial envolve um processo complexo, em que vítimas e opressores, na maioria das vezes, acabam não compreendendo seus papéis sociais exercidos, gerando uma alienação dos sujeitos (SOUZA, 2018).

Quando se discutem ações afirmativas para negros no Brasil, é fundamental destacar que, desde a década de 1930, o movimento negro esboçava as primeiras manifestações 
a favor de políticas que visassem a uma equidade racial no país; após a década de 1970, tornou-se mais atuante, em especial com a redemocratização do país na década de 1980.

Durante a III Conferência Mundial de Combate ao Racismo, Discriminação Racial, Xenofobia e Intolerância Correlata, realizada em Durban, em 2001, o Brasil reconheceu sua desigualdade racial e educacional, prometendo dar maior atenção a esse problema, implantando um programa de ação para o reconhecimento e o combate ao racismo.

Nos anos seguintes a esses eventos, diversas formas de políticas de ações afirmativas surgiram em universidades brasileiras. Machado (2013) ressalta que tais políticas foram inicialmente adotadas pelas universidades estaduais, como a Universidade Estadual do Rio de Janeiro (UERJ) e a Universidade Estadual do Sudoeste da Bahia (UESB); as primeiras federais foram a Universidade de Brasília $(\mathrm{UnB})$ e a Universidade Federal de Alagoas (UFAL), em 2003 e 2004, respectivamente. Nos anos posteriores, outras universidades também instituíram políticas de ação afirmativa. No Estado do Paraná, a Universidade Estadual de Londrina (UEL) e a Universidade Estadual de Ponta Grossa (UEPG) implantaram um sistema de cotas raciais nos vestibulares de 2005 e 2006, respectivamente.

No que se refere às universidades e aos institutos federais, é inegável o impacto da aprovação da Lei $n^{\circ}$. 12.711 (BRASIL, 2012), instituída pelo Supremo Tribunal Federal que estabeleceu a obrigatoriedade da adoção das políticas de cotas nas universidades federais. Enquanto isso, devido à autonomia garantida por lei nas universidades estaduais, o processo de incorporação das políticas de ação afirmativa foi mais lento (FERES JÚNIOR et al., 2017).

O Grupo de Estudos Multidisciplinares da Ação Afirmativa (GEMAA) realiza levantamento anual sobre a implantação das políticas de ação afirmativa em vigor nas universidades estaduais e federais brasileiras. A última publicação desse grupo de estudos se refere aos dados do ano de 2016, quando se constatou que, antes da Lei n ${ }^{\circ} .12 .711$, apenas 21 de 58 universidades federais possuía algum tipo de política de ação afirmativa. Com a obrigatoriedade exigida pela Lei, houve um incremento significativo na quantidade de vagas oferecidas aos diferentes grupos beneficiários (FERES JÚNIOR et al., 2017).

Em relação às universidades estaduais brasileiras, no ano de 2016, 89\% possuíam algum tipo de ação afirmativa. Segundo Feres Júnior et al. (2017), “A proporção de universidades estaduais com ação afirmativa aumentou apenas 8\% de 2012 a 2015, o que nos parece consequência mais da consolidação de um processo já existente desde a década passada [...], do que de uma influência da Lei 12.711/2012" (FERES JÚNIOR et al., 2017).

Ainda segundo os levantamentos do GEMAA, em 2016, em média 66\% das vagas em universidades estaduais eram destinadas à ampla concorrência; 18,5\% destinadas à reserva de vagas para estudantes de escola pública ou baixa renda; 12,7\% para pretos, pardos e/ou indígenas; e 2,3\% eram jovens com outros tipos de benefícios. Dessa maneira, observa-se que as universidades estaduais, mesmo que pioneiras, ainda precisam ampliar suas políticas de ações afirmativas para que consigam ao menos se equiparar às universidades federais.

Especificamente no que se refere ao Estado do Paraná, por meio da Lei 13.134 (PARANÁ, 2001) fixou-se a reserva de três vagas para serem disputadas entre os indígenas nos vestibulares das universidades estaduais. Cinco anos depois, a Lei 14.995 (PARANÁ, 2006) estabeleceu que essas vagas passassem de três para seis. 
Atualmente, o Estado do Paraná possui sete universidades estaduais. Entre elas, algumas já possuem o sistema de cotas raciais e sociais bem estabelecido, enquanto outras ainda estudam sua implantação ou o implantaram recentemente.

A Universidade Estadual de Maringá (UEM) introduziu um sistema de cotas sociais, a partir do vestibular de inverno de 2009, que leva em consideração o percurso escolar e a renda per capita familiar do estudante. No ano de 2018, o Núcleo de Estudos Interdisciplinares Afro-brasileiros da UEM fez uma solicitação para que fossem retomadas as discussões formais sobre a possibilidade da implantação de cotas raciais nessa universidade.

No ano de 2017, a Universidade Estadual do Norte do Paraná (UENP) aprovou um sistema de cotas sociais e raciais que passaram a destinar $40 \%$ das vagas para estudantes cotistas, sendo $20 \%$ delas para candidatos de escolas públicas e outros $20 \%$ para autodeclarados negros oriundos de escola pública (ASSESSORIA DE COMUNICAÇÃO SOCIAL DA UENP, 2017).

A Universidade Estadual de Ponta Grossa (UEPG) possui, atualmente, um sistema de cotas que reserva, por curso e turno, $50 \%$ das vagas aos candidatos oriundos de Instituições Públicas de Ensino, embutindo, dentro desse percentual, 10\% aos candidatos que se autodeclaram negros (UEPG, 2013).

A Universidade Estadual do Paraná (UNESPAR), desde o ano de 2015, está em um processo de discussão com a comunidade universitária e a sociedade sobre a possibilidade de implantação de um sistema de cotas racial e social. No ano de 2018, foi disposta uma minuta para consulta pública com toda a comunidade acadêmica. Essa universidade continua, no ano de 2019, orientando os Colegiados e Centros de Áreas a promoverem discussões nos campi, estendendo o convite a movimentos sociais locais interessados na temática (UNESPAR, 2019).

A Universidade Estadual do Centro-Oeste (UNICENTRO) e a Universidade Estadual do Oeste do Paraná (UNIOESTE) possuem, por sua vez, um sistema de cotas sociais que destinam, respectivamente, $20 \%$ e $50 \%$ das vagas a estudantes que tenham cursado integralmente o ensino médio em instituições públicas.

\section{As POLÍtTICAS DE PERMANÊNCIA PARA O ENSINO SUPERIOR NO BRASIL}

A adoção de ações afirmativas para o ingresso de estudantes negros e estudantes oriundos de escola pública nas universidades trouxe junto a necessidade da criação de políticas de garantia da permanência desses estudantes. Gomes (2009) ressalta que a discriminação e a falta de capital cultural e financeiro podem prejudicar a permanência dos jovens negros e pobres nas universidades.

A permanência estudantil deve circunscrever ações que envolvam apoio financeiro relacionadas à ordem da convivência na vida acadêmica e, assim, tornar-se capaz de integrar os estudantes na vida universitária e, por consequência, aos processos pedagógicos (CUNHA, 2017).

No entanto, de acordo com Dias e Costa (2015), a própria infraestrutura ofertada pelas instituições de ensino superior pode ser um diferencial para facilitar a permanência estu- 
dantil, como a disponibilidade de moradia estudantil, o apoio ao transporte, uma biblioteca bem equipada, refeitório, apoio para estudantes com deficiência física, entre outros instrumentos que auxiliam a adaptação e a permanência.

Segundo Cunha (2017, p. 66), as ações de favorecimento da permanência estudantil devem abranger diversas intervenções, por exemplo,

[...] a qualificação profissional dos docentes e demais servidores, à estruturação dos currículos, à distribuição/concentração de carga-horária nos turnos, assim como as ações direcionadas à oferta de condições minimamente razoáveis para os estudantes concluírem seus percursos acadêmicos, dentre outras.

A respeito dessa situação, Gomes (2009) enfatiza que, a partir dos anos 2000, alguns programas e projetos de ações afirmativas voltadas para a permanência dos jovens negros começam a surgir, porém com tempo de duração determinados e de forma muito isoladas. Por essa razão, a autora destaca a importância de esses programas se tornarem políticas de Estado e não resumirem apenas em distribuição de bolsas. É necessário, segundo ela, que essas políticas se difundam por diversas vertentes, propiciando instrumentos acadêmicos como: aulas de línguas estrangeiras, inserção em projetos de pesquisa e extensão, inserção da discussão racial nos currículos de graduação, preparação para a entrada na pós-graduação, implantação de ouvidorias de ações afirmativas, criação de espaços de intercâmbio e de diálogo entre os diferentes estudantes e a implantação de uma pró-reitoria de ação afirmativa que tenha o mesmo estatuto das outras pró-reitorias.

Ressalta-se, ainda, a importância dos Núcleos de Estudos Afro-Brasileiros (NEAB). Esses “[...] são núcleos que atuam na pesquisa, no ensino e na extensão no interior de universidades públicas (e algumas privadas) e têm a questão racial como foco central de investigação e intervenção" (GOMES, 2009, p. 198). Esses núcleos possuem articulações local, nacional e internacional e perfil político explícito de luta pela superação do racismo, além de posicionamento favorável às ações afirmativas e às cotas raciais.

Os NEABs se dedicam à permanência dos jovens negros cotistas e não cotistas no interior das universidades, além de realizar e orientar pesquisas sobre essas temáticas. Gomes (2009) destaca, ainda, que os NEABs conseguem questionar o caráter e a ação do conhecimento hegemônico na universidade, sempre eurocêntrico, produzido no contexto da modernidade ocidental, e que não dialoga com outros conhecimentos. Para a autora, os NEABs conseguem questionar o caráter e a ação do conhecimento hegemônico na universidade, sempre eurocêntrico, produzido no contexto da modernidade ocidental, e que não dialoga com outros conhecimentos.

Dias e Costa (2015, p. 56) apontam que, "Dada a multiplicidade de fatores relacionados à evasão e o desafio de garantir a permanência dos novos sujeitos no espaço acadêmico e com ensino de qualidade, têm crescido os esforços das IES por políticas institucionais que promovam a permanência dos alunos". Dessa forma, alguns decretos federais e algumas políticas afirmativas oriundas das próprias instituições de ensino superior buscaram, nos últimos anos, facilitar a permanência de estudantes negros.

Entre esses decretos destaca-se o Decreto Presidencial n. ${ }^{\circ}$ 6.096, de 24 de abril de 2007, que instituiu o Programa de Apoio a Planos de Reestruturação e Expansão das Uni- 
versidades Federais - REUNI (CUNHA, 2017). Esse programa tinha como objetivo principal "criar condições para a ampliação do acesso e permanência na educação superior, no nível de graduação, pelo melhor aproveitamento da estrutura física e de recursos humanos existentes nas universidades federais" (BRASL, 2007a). Entre as ações definidas nesse plano, destacam-se: redução das taxas de evasão, ocupação de vagas ociosas e aumento de vagas de ingresso, especialmente no período noturno; revisão da estrutura acadêmica, com reorganização dos cursos de graduação e atualização de metodologias de ensino aprendizagem, buscando a constante elevação da qualidade e a ampliação de políticas de inclusão e assistência estudantil.

Após a criação do REUNI, foi instituído, pelo governo federal, o Programa Nacional de Assistência Estudantil (PNAES), para subsidiar a permanência de estudantes em cursos de graduação, por meio da Portaria Normativa $n^{\circ}$. 39, de 12 de dezembro de 2007 (BRASIL, 2007b).

Segundo a Portaria, esse Programa destina-se a realizar ações de assistência estudantil vinculadas ao desenvolvimento de atividades de ensino, pesquisa e extensão, aos estudantes que estejam matriculados em cursos de graduação presencial das Instituições Federais de Ensino Superior (IFES). Os objetivos principais do PNAES são:

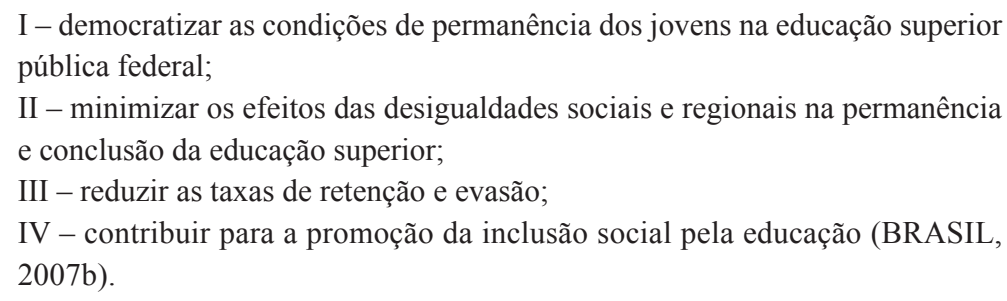

As ações do PNAES devem ser realizadas nas seguintes áreas: moradia estudantil, alimentação, transporte, assistência à saúde, inclusão digital, cultura, esporte, creche e apoio pedagógico.

No entanto, apesar de ainda vigente, o Programa Nacional de Assistência Estudantil vem sofrendo crescentes quedas no volume de recursos destinados. De 2008 a 2016, o PNAES recebeu volumes crescentes de recursos (de R\$ 125 milhões em 2008 a R \$ 1 bilhão em 2016); mas, a partir desse ano, houve uma queda nessas destinações, passando para R\$ 987 milhões em 2017 e R\$ 957 milhões em 2018. Como consequência dessa diminuição de recursos, foi observada uma redução dos estudantes cobertos pelas políticas do PNAES (como políticas de permanência nas áreas de alimentação, moradia, transporte e também nas bolsas permanência institucional) entre os anos de 2014 e 2018 (FONAPRACE, 2019).

Além desses decretos, destaca-se que no Plano Nacional de Educação (PNE) de 2014, aprovado com a inserção de metas para a ampliação das políticas de inclusão e assistência estudantil dirigidas às instituições públicas, com objetivo de redução:

[...] das desigualdades étnico-raciais e regionais no acesso e na permanência na modalidade, inclusive mediante a adoção de políticas afirmativas, na forma da lei [...] (BRASIL, 2014). 
É possível destacar ainda alguns programas e ações voltadas para a área acadêmica presentes em universidades federais e estaduais que, de acordo com Gisi e Pegorini (2016), também favorecem a permanência e a melhoria da aprendizagem dos estudantes, como o Programa Institucional de Bolsas de Iniciação Científica (PIBIC), Programa de Monitoria, o Programa de Iniciação à Docência (PIBID) e o apoio à participação em eventos; além disso, destaca-se também o Programa de Residência Pedagógica, criado no ano de 2018.

O governo federal, em maio de 2013, por meio da Portaria $n^{\circ} .389$, instituiu ainda o Programa de Bolsa Permanência que se destina à concessão de bolsas de permanência a estudantes de graduação de instituições federais de ensino superior e que possui como objetivos:

I - viabilizar a permanência, no curso de graduação, de estudantes em situação de vulnerabilidade socioeconômica, em especial os indígenas e quilombolas;

II - reduzir custos de manutenção de vagas ociosas em decorrência de evasão estudantil;

III - promover a democratização do acesso ao ensino superior, por meio da adoção de ações complementares de promoção do desempenho acadêmico (BRASIL, 2013).

Segundo a Portaria $n^{\circ} .389 / 2013$, a Bolsa Permanência é um auxílio financeiro com o objetivo de minimizar as desigualdades sociais e étnico-raciais e contribuir para a permanência e consequente diplomação dos estudantes em situação de vulnerabilidade socioeconômica. Atualmente, estudantes que possuem bolsas do Programa Universidade Para Todos (PROUNI) também podem pleitear uma Bolsa Permanência.

Diferente das Universidades Federais, as Universidades Estaduais brasileiras possuem autonomia didático-científica, administrativa e de gestão financeira e patrimonial, garantida pela Constituição Federal (BRASIL, 1988). Dessa forma, cada instituição determina se terá políticas de ação afirmativa e como estas se darão. Estudos sobre a implantação e os resultados dessas políticas em universidades estaduais estão ganhando cada vez mais espaço nas discussões científicas.

A respeito dessas pesquisas, é possível mencionar a dissertação de Duarte Júnior (2013), a qual aborda os desafios da permanência para estudantes cotistas da Região Nordeste; a dissertação de Oliveira (2015), sobre as políticas de permanência na Universidade Estadual de Feira de Santana; e o artigo de Maciel, Lima e Gimenez (2016), acerca das políticas de permanência nas Instituições Federais e Estaduais de Educação Superior do Estado de Mato Grosso. No que se refere à Universidade Estadual de Londrina, destacam-se os estudos de Silva (2014) e Souza (2018), com reflexões sobre os desafios e os acertos na implantação de reserva de vagas raciais e sociais nessa Universidade.

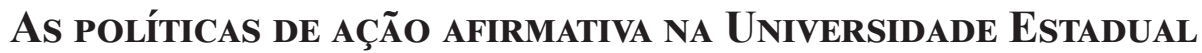 DE LONDRINA}

A Universidade Estadual de Londrina começou o debate sobre as ações afirmativas devido à demanda reivindicada pelo Movimento Negro de Londrina, que estava em sintonia com os demais movimentos negros nacionais e com o avanço do debate após a Conferência 
de Durban, de 2001 (SILVA; PACHECO, 2012). A autora destaca que a implantação do sistema de cotas na UEL deu-se a partir de um processo iniciado em 2002 e que envolveu as comunidades interna e externa, resultando em uma proposta ao Conselho Universitário, em julho de 2004, medida que, posteriormente, foi aprovada.

No ano de 2004, a primeira proposta, a Resolução 78/2004 (UEL, 2004), regulamentou o sistema de cotas e condicionou o número de vagas à proporção de inscritos em cada curso no vestibular. O primeiro artigo dessa resolução estabelece:

[...] até 40\% (quarenta por cento) das vagas de cada curso de graduação, ofertadas em Concurso Vestibular pela Universidade Estadual de Londrina, serão reservadas a estudantes oriundos de Instituições Públicas de Ensino, sendo que até metade das vagas decorrentes da aplicação deste percentual deverão ser reservadas a candidatos que se autodeclarem negros (UEL, 2004).

No primeiro vestibular, o candidato que "[...] concorresse às vagas destinadas aos negros não poderia concorrer às reservadas aos estudantes de escola pública ou universal" (SILVA; PACHECO, 2012, p. 91). Cada inscrito ficava restrito à concorrência daquela vaga à qual se inscreveu, o que, de acordo com os autores, gerou menores chances de ingresso de jovens negros.

Somente no ano de 2006, os candidatos negros passaram a concorrer a $100 \%$ das vagas; sendo assim, ingressavam por cotas aqueles que não conseguiam ingressar nem pelo sistema de ampla concorrência, nem pelo sistema de escola pública. Entre os anos de 2009 e 2010, retomou-se o modelo de sistema utilizado no primeiro ano de implantação (2005), o que novamente acarretou que estudantes negros que se inscrevessem pelo sistema de cotas concorreriam apenas às vagas destinadas à cota racial, ou seja, mesmo possuindo pontuação para o ingresso pelo sistema universal, não podiam fazer a migração, e permaneciam nas vagas reservadas para negros, o que diminuiu as chances de ingresso de muitos estudantes negros durante esse período. Essa situação se modificou em 2011, quando retornou ao padrão de 2006-2008, sob a nova administração da universidade (SILVA; PACHECO, 2012).

Em 2012, foi realizada a avaliação do sistema de cotas e constatou-se que a excelência da universidade fora mantida. "Todos os dados apresentados pela Pró-Reitoria de Graduação confirmaram que houve maior inclusão de estudantes que não ingressariam na UEL caso não houvesse o sistema de cotas, especialmente as reservadas para estudantes de instituições públicas" (SILVA, 2014, p. 228). Nesse ano, também houve mudanças: a concorrência passou a ser $20 \%$ dos números de vagas do curso e não dos inscritos, como era no sistema anterior. Vale ressaltar, como exemplo, o elitizado curso de medicina que, a partir do vestibular de 2013, com a aplicação do novo sistema, passou a ter 16 estudantes negros ingressando apenas pelo sistema de cotas raciais, fora aqueles que migravam para a reserva de vagas de escola pública ou para o sistema universal. Esse mecanismo, com certeza, consolidou a presença significativa de negros em cursos de alta concorrência.

Na segunda avaliação de cotas, em 2017, a Resolução 008/2017 (UEL, 2017) estabeleceu 20 anos de duração para o novo sistema, além de reservar 5\% das vagas do Processo Seletivo Vestibular e no Sistema de Seleção Unificada do Ministério da Educação (SISU) ${ }^{1}$

1 Alguns cursos não aderiram ao Sistema de Seleção Unificada, sendo eles: Administração, Arquitetura e Urbanismo, Artes Visuais, Design de Moda, Design Gráfico, Engenharia Civil, Jornalismo, Letras (Inglês), Medicina, Música e Relações Públicas. 
a candidatos que se autodeclararem negros de qualquer percurso escolar, ou seja, de escolas públicas, privadas ou portadores de diplomas de ensino superior. Essa nova reserva de vaga foi proposta pela Comissão responsável ${ }^{2}$ por avaliar o sistema de cotas da Universidade e perceber que, desde 2005, alguns estudantes negros bolsistas em escolas particulares ou que pagaram um valor baixíssimo para fazer um curso de Educação de Jovens e Adultos - acometidos, igualmente como os de escola pública, pela crueldade do racismo - não conseguiam ingressar pelo sistema de cotas. Essa preocupação foi apresentada ao Conselho Universitário, que concordou com a proposta e instituiu mais 5\% de cotas raciais para qualquer percurso escolar, a partir das vagas universais, que ficaram com 55\%.

\section{As POLÍticas de PERMANÊNCIA ESTUdANTIL NA UNIVERSIDADE EsTAdUAL DE LONDRINA}

Souza (2018) e Silva (2014) destacam os avanços obtidos nos últimos anos com a crescente entrada de estudantes negros por meio do sistema de cotas na UEL. No entanto, enfatizam também a necessidade de criação de políticas de permanência, uma vez que o ingresso desses estudantes no ensino superior não garante que eles permaneçam e se formem.

Uma das primeiras ações que visaram à permanência dos estudantes cotistas raciais na UEL foi a parceria com o Programa Integrado de Ações Afirmativas para Negros Brasil Afroatitude, desenvolvido em 2005. O programa destinava 500 bolsas no valor de $\mathrm{R}$ \$ 241,51 mensais (parâmetro CNPq - Iniciação Científica) para as universidades que adotaram o regime de cotas raciais. Assim, essas bolsas foram distribuídas, igualmente, segundo os planos de ação apresentados pelas universidades participantes, sendo, portanto, 50 bolsas para cada universidade (BRASIL, 2004).

Após o processo de avaliação do sistema de cotas de 2011, a comissão responsável, ao perceber que a porcentagem de reserva de vagas para estudantes negros não era atingida em alguns cursos, indicou a criação de um Programa que desse suporte à divulgação das cotas nas escolas públicas de Londrina e região, além de estabelecer algumas parcerias com o Serviço de Bem Estar à Comunidade (SEBEC), para a promoção da permanência dos estudantes cotistas da UEL. Assim, em 2013, foi criado o Programa de Apoio ao Acesso e Permanência para a Formação de Estudantes da UEL (PROPE), com o objetivo de atuar em três frentes: no acesso, no apoio pedagógico e na assistência estudantil. O PROPE proporciona que estudantes da UEL visitem escolas públicas para divulgar informações sobre a Universidade, como formas de ingresso, cursinho pré-vestibular e o sistema de cotas (SILVA, 2014). Dessa forma, o Programa procura levar informação para estudantes da rede básica de ensino a respeito da Universidade, de modo a garantir oportunidades para que todos tenham acesso às informações necessárias, caso queiram cursar uma instituição de ensino superior pública, gratuita e de qualidade.

Além do PROPE, a Universidade Estadual de Londrina possui, atualmente, outras ações que auxiliam na permanência de estudantes cotistas, como a moradia estudantil, a Bolsa Permanência, o subsídio RU (Restaurante Universitário) e o empréstimo de instru-

2 Essa ampliação do sistema de cotas foi elaborada pela Câmara de Graduação e instituída pela Resolução 008/2017 (UEL, 2017). 
mentos odontológicos. Todas essas políticas ficam sob a responsabilidade do SEBEC que, por meio de uma seleção unificada, avalia a condição financeira da família e as despesas com tarifas públicas dos candidatos por meio de documentação comprobatória e entrevista.

Segundo o Edital 001/2019 (UEL, 2019), os programas ofertados possuem o objetivo de "minimizar as desigualdades existentes entre os estudantes, viabilizando recursos mínimos necessários para a permanência e a formação com qualidade de estudantes em situação de vulnerabilidade socioeconômica".

A Moradia Estudantil está localizada no Campus Universitário e, atualmente, oferece até 84 vagas para estudantes regularmente matriculados na UEL, prioritariamente de graduação, sendo quatro dessas vagas reservadas a pessoas com deficiência. Além disso, o candidato que for classificado para a vaga na Moradia Estudantil terá direito ao subsídio ampliado no Restaurante Universitário.

A Bolsa Permanência para estudantes de graduação diz respeito às 100 bolsas no valor de $\mathrm{R} \$ 300,00$, com duração de até 12 meses, até o próximo processo de seleção desse benefício, a partir da data da divulgação do resultado final. O subsídio ampliado para as refeições no Restaurante Universitário refere-se às 4.500 refeições ofertadas por mês a estudantes comprovadamente de baixa renda e que foram selecionados pelo processo unificado do SEBEC.

O Programa de Empréstimo de Instrumentos Odontológicos tem como objetivo ofertar aos estudantes do curso de odontologia, na categoria de empréstimo, kits de instrumentais odontológicos disponibilizados pelo Colegiado do Curso de Odontologia, para o desenvolvimento das práticas acadêmicas (UEL, 2019).

Ressalta-se, também, o Programa Institucional de Apoio a Ações Afirmativas para Inclusão Social - Pesquisa e Extensão Universitária - Bolsa de Inclusão Social / Fundação Araucária, existente desde o ano de 2005, que distribui bolsas a estudantes cotistas. Nos anos de 2017 e 2018, o total dessas bolsas na UEL foi 136 e 131, respectivamente.

Segundo o último Edital desse Programa - Edital nº 074/2018 (UEL, 2018) -, essas bolsas são destinadas a estudantes cotistas com o objetivo de "Incentivar a formação de recursos humanos para projetos de pesquisa, ensino e extensão universitária, direcionadas a temas de interesse social e favorecer o acesso e a integração à cultura acadêmica dos estudantes ingressantes no ensino superior por meio do sistema de cotas sociais" (UEL, 2018).

No que se refere às ações afirmativas destinadas a povos indígenas na UEL, destaca-se uma conquista coletiva, sobretudo da Comissão Universidade para Índios (CUIA): o Vestibular dos Povos Indígenas do Paraná, com seis vagas suplementares a cada Vestibular das sete IES estaduais e dez vagas na Universidade Federal do Paraná (UFPR), assim como a organização do "Ciclo Intercultural de Iniciação Acadêmica", no qual os estudantes indígenas da UEL permanecem no primeiro ano de ingresso na Universidade, tendo aulas de todas as áreas do conhecimento, ambientando-se academicamente com a universidade, e só no ano seguinte escolhem o curso de graduação de seu interesse (BRANDÃO; CAMPOS; LIMA, 2018).

A UEL possui também uma parceria com a Vara de Execuções Penais do Município de Londrina, que possibilita a liberação de candidatos com privação de liberdade (em regime aberto, semiaberto ou fechado), para a realização dos Processos Seletivos de Ingresso (Ves- 
tibular e SISU), sem pagamento de taxas. No mês de julho de 2019, o Cursinho Especial Pré-Vestibular (CEPV) da UEL passou a ofertar aulas a 50 apenados da Penitenciária Estadual de Londrina (PEL II), com o objetivo de dar oportunidades aos apenados que possuam ensino médio completo e que se encontram em preparação para o regime semiaberto de ingressarem em um curso de ensino superior. Além disso, a cada 12 horas/aula, os apenados diminuem sua pena em um dia.

Cabe destacar que esses estudantes, ao se tornarem estudantes universitários, carecem de ações de maior apoio para atividades de ensino/pesquisa/extensão fora do turno, de bolsas de estudos, de materiais didáticos para pesquisas e complementação dos estudos, de apoio nas atividades que demandam viagens acadêmicas ou em projetos/programas desenvolvidos fora do espaço da universidade (BRANDÃO; CAMPOS; LIMA, 2018).

Mais recentemente, em março de 2018, preocupado com o acesso dos refugiados à educação superior, o PROPE protocolou na UEL, em parcerias com a Pastoral do Migrante, a Cáritas e outros movimentos/entidades representativos, a Minuta de Resolução que estabelece normas para isenção de taxas de revalidação de diplomas de graduação e de pós-graduação expedidos por estabelecimentos estrangeiros de ensino superior, requerida por imigrantes em situação regular, de forma provisória ou permanente, em condição de vulnerabilidade socioeconômica, residentes no Estado do Paraná (BRANDÃO; CAMPOS; LIMA, 2018). Em 27 de março de 2019, foi aprovada, pela Assembleia Legislativa do Paraná, a Lei Estadual 19.829 (PARANÁ, 2019), que dispõe sobre a admissão e o reconhecimento, no Estado do Paraná, de diplomas de pós-graduação stricto sensu (mestrado e doutorado) originários de cursos ofertados de forma integral presencial nos países do Mercado Comum do Sul e em Portugal.

Por fim, alguns eventos também podem ser citados como fortalecedores das discussões sobre permanência universitária, como: o I Fórum de Permanência Estudantil e Direitos Humanos, realizado em maio de 2018 com o objetivo de discutir com a comunidade universitária, de forma ampla e democrática, os entraves e as propostas para a permanência na UEL. Outras iniciativas ainda podem ser destacadas para o ingresso e a permanência de cotistas, como o Cursinho Pré-Vestibular gratuito para estudantes de baixa renda egressos do Ensino Médio; os cursos de formação continuada com professores da Educação Básica, realizados principalmente em parceria com o NEAB e o Laboratório de Cultura e Estudos Afro-Brasileiros (LEAFRO) e o acompanhamento dos processos de reformulação curricular das licenciaturas, com a implantação da Resolução CNE/CP n . 02/2015, que, entre outros conteúdos, exige a inserção das diversidades étnico-raciais nos currículos de formação inicial e continuada de professores (BRANDÃO; CAMPOS; LIMA, 2018).

Ainda que tais políticas de permanência não consigam abranger todos os estudantes que necessitam dessas ações na UEL, essas medidas constituem-se como um avanço no processo de democratização dessa instituição, além de caminhar para uma verdadeira "[...] representatividade sociocultural nos distintos espaços sociais" (SOUZA, 2018, p. 162). 


\section{A PERCEPÇÃo dOS EGRESSOS/AS do SISTEMA DE COTAS RACIAIS DA UEL QUANTO ÀS POLÍTICAS DE PERMANÊNCIA}

Tendo em vista a relevância das políticas de cotas nas universidades, mas considerando que, isoladamente, apenas elas não são suficientes para uma verdadeira democratização do ensino superior, a presente pesquisa buscou realizar um levantamento sobre as concepções dos estudantes cotistas raciais egressos da UEL a respeito das políticas de permanência presentes nessa universidade, bem como, possíveis dificuldades encontradas durante sua formação.

A pesquisa foi realizada por meio de questionário on-line, com estudantes cotistas raciais formados entre os anos de 2010 e 2016, período escolhido porque abrange cursos com cinco anos de duração pós-2005. Dos 808 e-mails enviados com o link para o questionário, apenas 39 retornaram por erro ou falha na entrega ao destinatário. No total, foram obtidas 200 respostas, ou seja, $24,7 \%$ dos cotistas raciais que se formaram entre os anos de 2010 a 2016 responderam ao questionário.

$\mathrm{Na}$ Tabela 1, especifica-se o total de estudantes cotistas raciais formados no período analisado.

Tabela 1 - Total de estudantes cotistas raciais que se formaram entre 2010-2016.

\begin{tabular}{|c|c|}
\hline Ano & Formandos \\
\hline 2010 & 116 \\
\hline 2011 & 142 \\
\hline 2012 & 106 \\
\hline 2013 & 100 \\
\hline 2014 & 116 \\
\hline 2015 & 130 \\
\hline 2016 & 98 \\
\hline Total Geral & 808 \\
\hline
\end{tabular}

Fonte: Pró-Reitoria de Graduação da Universidade Estadual de Londrina (2018).

A Tabela 2 expressa o número total de estudantes que responderam ao questionário por ano de ingresso. Os egressos que mais responderam ao questionário on-line foram os ingressantes dos anos de 2008, 2010 e 2011. 
Tabela 2 - Total de estudantes cotistas raciais que responderam ao questionário por ano de ingresso.

\begin{tabular}{c|c|c}
\hline Ano de ingresso & Número & Porcentagem \\
\hline 2005 & 9 & $4,5 \%$ \\
\hline 2006 & 15 & $7,5 \%$ \\
\hline 2007 & 27 & $13,5 \%$ \\
\hline 2008 & 35 & $17,5 \%$ \\
\hline 2009 & 18 & $9 \%$ \\
\hline 2010 & 31 & $15,5 \%$ \\
\hline 2011 & 30 & $15 \%$ \\
\hline 2012 & 22 & $11 \%$ \\
\hline $\begin{array}{c}\text { Resposta } \\
\text { inconcludente }\end{array}$ & 13 & $6,5 \%$ \\
\hline
\end{tabular}

Fonte: Dados da pesquisa (2018).

Em relação às políticas de permanência e às dificuldades encontradas por esses estudantes durante o período de graduação, foram realizados cinco questionamentos, e suas respostas serão exploradas nas Tabelas 3, 4, 5, 6 e 7 .

A primeira pergunta referente à permanência foi "Durante a graduação, precisou de alguma bolsa para permanecer na Universidade? Qual?" As respostas a esse questionamento foram sintetizadas na Tabela 3.

Tabela 3 - Necessidade de bolsa durante a graduação.

\begin{tabular}{|c|c|c|c|}
\hline $\begin{array}{c}\text { Total de } \\
\text { respostas }\end{array}$ & Em \% & & Especificação da bolsa \\
\hline 123 & 61,5 & Não & \\
\hline 1 & 0,5 & Não respondeu & \\
\hline 4 & 2 & Sim & Não especificado \\
\hline 15 & 7,5 & Sim & Bolsa de Iniciação Científica \\
\hline 20 & 10 & Sim & Bolsa de Inclusão Social - Fundação Araucária \\
\hline 10 & 5 & Sim & PIBID \\
\hline 9 & 4,5 & $\operatorname{Sim}$ & Bolsa Fundação Araucária \\
\hline 7 & 3,5 & Sim & Bolsa de estágio \\
\hline 2 & 1 & Sim & Iniciação Científica (CNPq) e Fundação Araucária \\
\hline 2 & 1 & Sim & Bolsa de Extensão da Fundação Araucária \\
\hline 1 & 0,5 & Sim & Programa de Educação Tutorial (PET) \\
\hline 1 & 0,5 & $\operatorname{Sim}$ & Bolsa de Inclusão Social e PIBID \\
\hline 1 & 0,5 & Sim & Bolsa Capes, socioeconômica \\
\hline 1 & 0,5 & Sim & Moradia Estudantil \\
\hline 1 & 0,5 & Sim & $\begin{array}{c}\text { Bolsa para Professor do Curso Especial Pré- } \\
\text { Vestibular }\end{array}$ \\
\hline 1 & 0,5 & Sim & Iniciação Científica, bolsista da Embrapa \\
\hline 1 & 0,5 & Sim & Programa de Atividade Física - NAFI \\
\hline
\end{tabular}

Fonte: Dados da pesquisa (2018). 
Por meio da Tabela 3, observa-se que mais da metade $(61,5 \%)$ dos egressos que responderam ao questionário não foram contemplados ou não precisaram de bolsas para permanecer na graduação. No entanto, por meio dos relatos nas respostas, foi possível constatar que uma parte significativa dos entrevistados não teve acesso a essas políticas, pois muitas bolsas, como as de pesquisa e extensão, tinham como requisito dedicação de 20 horas extracurriculares, e boa parte deles mantinha vínculos empregatícios, o que impossibilitava a participação em tais projetos e pesquisas.

Mesmo assim, deve-se ressaltar que as Bolsas de Inclusão Social foram citadas por $10 \%$ dos entrevistados, demonstrando a importância de programas dessa natureza para a permanência estudantil. Outras bolsas, como as do Programa Institucional de Bolsas de Iniciação à Docência, as Bolsas de Iniciação Científica e os estágios remunerados, entre outras políticas, também foram citados pelos egressos como um apoio financeiro fundamental em alguns casos, o que sustentou a permanência durante a graduação. Posteriormente, foi perguntado aos egressos quais as dificuldades encontradas para se manter no curso durante a graduação. As respostas a essa pergunta foram sintetizadas na Tabela 4.

Tabela 4 - Dificuldades de permanência.

\begin{tabular}{|c|c|c|}
\hline $\begin{array}{l}\text { Teve dificuldades de } \\
\text { manter-se no curso? }\end{array}$ & Egressos & O tipo de dificuldades \\
\hline Não & 108 & \\
\hline Não respondeu & 3 & \\
\hline Sim & 67 & $\begin{array}{c}\text { Financeira (transporte, alimentação, moradia, material } \\
\text { para as atividades acadêmicas e fotocópias) }\end{array}$ \\
\hline Sim & 18 & Conciliar a universidade com trabalho / Falta de tempo \\
\hline Sim & 14 & $\begin{array}{l}\text { Falta de apoio pedagógico para acompanhar o ritmo } \\
\text { acadêmico }\end{array}$ \\
\hline Sim & 4 & $\begin{array}{c}\text { Violência familiar, assédio moral e intelectual e/ou } \\
\text { discriminação }\end{array}$ \\
\hline Sim & 3 & Problemas de saúde \\
\hline Sim & 1 & Conseguir estágio à tarde \\
\hline Sim & 1 & Maternidade \\
\hline
\end{tabular}

*Cada entrevistado pode ter elencado mais de um tipo de dificuldade.

Fonte: Dados da pesquisa (2018).

Quase metade dos discentes afirmaram ter encontrado algum tipo de dificuldade, e entre essas dificuldades, evidenciadas na Tabela 4, a financeira foi a mais citada ( $32 \%$ dos entrevistados). As dificuldades relatadas envolviam desde alimentação, moradia e transporte, até fotocópias, impressões, livros e materiais necessários à prática acadêmica de alguns cursos, como odontologia e jornalismo. Destacam-se também como principais problemas, a falta de tempo devido ao trabalho e a necessidade de apoio pedagógico. Esse cenário confirma o que Gomes (2009) ressalta em relação à necessidade de políticas que garantam a efetiva permanência de estudantes negros que perpassem não apenas o aspecto financeiro e o psicológico, mas, também, o pedagógico. 
Segundo Bourdieu, apesar de ainda se relacionar o sistema escolar como uma possibilidade de mobilidade social, tudo parece demonstrar que esse sistema serve para a conservação social, pois "[...] fornece a aparência de legitimidade às desigualdades social, e sanciona a herança cultural e o dom social tratado como dom natural" (BOURDIEU, 1999, p. 41). Isso se dá porque a cultura da elite é muito próxima da cultura escolar. Dessa forma, o capital cultural de cada família será responsável pela diferença apresentada inicialmente pelas crianças no processo escolar e, por conseguinte, nas suas taxas de êxito, considerando que famílias pertencentes à cultura da elite econômica provavelmente estarão mais próximas da cultura escolar (BOURDIEU, 1999).

Assim, o sistema escolar não considera as desigualdades sociais, ao tratar "[...] todos os educandos, por mais desiguais que sejam eles de fato, como iguais em direitos e deveres, o sistema escolar é levado a dar sua sanção às desigualdades iniciais diante da cultura" (BOURDIEU, 1999, p. 53).

E são estudantes com bagagens culturais distintas que agora ingressam pelo sistema de cotas das universidades. Ainda segundo Bourdieu (1999), esses estudantes das classes populares serão julgados segundo valores das classes privilegiadas, até mesmo porque o modus operandi da Universidade é pautado nos valores das classes hegemônicas.

À vista dessas desigualdades resultantes do sistema capitalista, compreende-se a importância do apoio pedagógico aos diferentes discentes que ingressam no ensino superior, uma vez que cada um possui bagagens culturais distintas, devido às diversas realidades vivenciadas.

A terceira questão (Tabela 5) diz respeito às discriminações que esses egressos sofreram durante o tempo em que permaneceram na UEL.

Tabela 5 - Preconceito e discriminação durante a graduação.

\begin{tabular}{|l|l|l|l|}
\hline Resposta & $\begin{array}{l}\text { Número } \\
\text { total }\end{array}$ & $\begin{array}{l}\mathbf{E m} \\
\mathbf{\%}\end{array}$ & $\begin{array}{l}\text { Descrição do tipo de discriminação sofrida ou } \\
\text { presenciada }\end{array}$ \\
\hline Não respondeu & 3 & 1,5 & \\
\hline Não & 125 & 62,5 & \\
\hline Não & 3 & 1,5 & Por ser pardo(a), nunca sentiu discriminação \\
\hline Não & 9 & 4,5 & Discriminação apenas fora da UEL \\
\hline Não & 6 & 3 & Não diretamente, mas já ouviu frases e /ou atos racistas \\
\hline Sim & 11 & 5,5 & Sem especificação \\
\hline Sim & 17 & 8,5 & $\begin{array}{l}\text { Preconceito velado, atos indiretos que acabaram } \\
\text { prejudicando ou menosprezando }\end{array}$ \\
\hline Sim & 18 & 9 & $\begin{array}{l}\text { Discriminações mais explícitas - tachado de cotista, } \\
\text { tachado de incapaz }\end{array}$ \\
\hline Sim & 3 & 1,5 & Discriminações por parte de docentes \\
\hline Sim & 1 & 0,5 & Mais por ser gorda do que por ser negra \\
\hline Sim & 1 & 0,5 & Pela alta concorrência do curso \\
\hline Não especificou & 2 & 1 & Preconceito social maior que o racial \\
\hline Talvez & 1 & 0,5 & Mas não percebia \\
\hline
\end{tabular}

Fonte: Dados da pesquisa (2018). 
A Tabela 5 evidencia que $61,5 \%$ dos entrevistados disseram não ter sofrido qualquer tipo de discriminação durante o período de graduação. No entanto, considerando que o racismo se manifesta em diversos espaços e escalas, e muitas vezes de formas sutis, é necessário que a escola busque, por meio da Lei 10.639 (BRASIL, 2003), que estabelece a inclusão no currículo oficial da Rede de Ensino a obrigatoriedade da temática "História e Cultura Afro-Brasileira", a conscientização dos discentes quanto a manifestações racistas que se expressam de várias formas. Espera-se, com essa iniciativa, o preparo dos estudantes na identificação e no enfrentamento de situações de racismo, mesmo aqueles que surgem de maneira sutil e velada (BRASIL, 2003).

Segundo Santos (2009), o racismo muitas vezes torna-se mais difícil de ser identificado e compreendido, pois é internalizado e naturalizado por discursos discriminantes e, como consequência, "Algumas vítimas negam que estejam oprimidas ou então aceitam sua condição, como se fosse um destino que a vida lhes proporcionou" (SANTOS, 2009, p. 58). A identificação dessas discriminações torna-se mais difícil porque o acesso ao ensino é "[...] dificultado, não por normas e regras escritas e visíveis, mas por obstáculos formas presentes nas relações sociais que se reproduzem nos espaços institucionais e públicos" (SANTOS, 2009, p. 58).

Esse racismo velado muitas vezes é exteriorizado na universidade, pela própria ausência (ou baixa presença) de docentes e estudantes negros no meio acadêmico. Segundo Carvalho (2013), havia um silêncio sobre o racismo nas universidades, e somente com a introdução das cotas, no início do século XXI, passaram a existir discussões a respeito desse problema. Iniciaram-se indagações quanto à baixa presença de estudantes e docentes negros que pudessem servir na construção de uma autoimagem positiva nos estudantes negros para resistir aos embates do meio acadêmico.

No entanto, há que se considerar que uma parte dos entrevistados $(8,5 \%)$ também relatou formas de discriminações explícitas, como comentários negativos e ofensivos pelo fato de terem ingressado pelo sistema de cotas raciais. Exemplos de relatos dessa natureza foram:

\footnotetext{
No dia da entrevista na COPS, havia um estudante com camiseta de agronomia (havia alguma numeração, tipo turma xx agronomia). Escutei ele apontando para os estudantes afrodescendentes que estavam esperando para a entrevista e disse: 'olha os negro folgado que roubam vaga dos outros'. Depois disso, demorei mais de um ano para autodeclarar que tinha prestado vestibular pela política de cotas raciais (ENTREVISTADO 79).

Sim, já ouvi diversas vezes outros alunos questionarem a entrada de negros ser somente devido a cotas, de forma preconceituosa, justificando ser privilégio (ENTREVISTADO 80).
}

Outros relatos de discriminações explícitas foram em relação à dificuldade para fazer amigos, situações de constrangimento causadas por professores, questionamentos quanto à pontuação realizada no vestibular e comentários negativos relacionados às políticas de cotas.

Uma parte dos egressos cotistas ressaltou que alguns professores e colegas não acreditavam que poderiam se formar ou se destacar academicamente. No entanto, a tese de Souza (2018) comprovou que a taxa de permanência entre os cotistas raciais é mais alta do que os estudantes que ingressaram pelo sistema universal e também pelo sistema de cota social 
(escola pública). Além disso, comprovou-se que esses estudantes cotistas têm rendimentos acadêmicos muito próximos aos que ingressaram pelas vagas universais, apresentando uma diferença ínfima nas médias gerais.

Pesquisou-se, também junto a esses egressos cotistas, a opinião pessoal sobre as políticas de permanência da UEL. As respostas foram sistematizadas na Tabela 6 .

Tabela 6 - Opinião sobre as políticas de permanência da UEL (satisfatória ou insatisfatória).

\begin{tabular}{|c|c|c|c|}
\hline Respostas & $\begin{array}{l}\text { Número } \\
\text { Total }\end{array}$ & $\begin{array}{l}\mathbf{E m} \\
\%\end{array}$ & Justificativas das respostas \\
\hline Sim & 35 & 17,5 & *Sem justificativa \\
\hline Sim & 8 & 4 & *Resposta evasiva e/ou confusa \\
\hline Sim & 37 & 18,5 & As políticas eram satisfatórias \\
\hline Sim & 15 & 7,5 & As políticas poderiam melhorar / e ser mais divulgadas \\
\hline Sim & 2 & 1 & Mas a UEL não deveria ter um sistema de cotas \\
\hline Não & 11 & 5,5 & *Sem justificativa \\
\hline Não & 45 & 22,5 & As políticas deveriam ser ampliadas e melhoradas \\
\hline Não & 7 & 3,5 & $\begin{array}{l}\text { Necessário criar políticas de acompanhamento dos egressos / } \\
\text { apoio financeiro, psicológico e pedagógico / investigação de } \\
\text { discriminações raciais dentro na Universidade. }\end{array}$ \\
\hline Não & 1 & 0,5 & $\begin{array}{l}\text { Acredita que não deve haver políticas voltadas à } \\
\text { permanência do cotista racial }\end{array}$ \\
\hline Não sei & 2 & 1 & Não há necessidade de políticas de permanência \\
\hline \multirow[t]{4}{*}{ Não sei } & 25 & 12,5 & *Sem justificativa \\
\hline & 2 & 1 & $\begin{array}{l}\text { O estudante tem que buscar sozinho sua forma de } \\
\text { permanência }\end{array}$ \\
\hline & 1 & 0,5 & $\begin{array}{l}\text { Nâo recorda de qualquer política na época em que era } \\
\text { estudante }\end{array}$ \\
\hline & 4 & & Não pode ser apenas para negros, mas também para pobres \\
\hline $\begin{array}{l}\text { Não } \\
\text { respondeu }\end{array}$ & 5 & 2,5 & *Sem justificativa \\
\hline
\end{tabular}

Fonte: Dados da pesquisa (2018).

Parte significativa dos entrevistados (30\%) afirmou que essas políticas de permanência poderiam ser melhoradas, ampliadas e mais divulgadas, para que possam atingir mais estudantes. Destaque para a resposta de dois entrevistados que, mesmo tendo ingressado na Universidade pelo sistema de cotas raciais, afirmaram que não veem necessidade de políticas de permanência ou que o estudante deve buscar sozinho os meios de permanência, e que o sistema de cotas deveria deixar de existir.

Dessa forma, essas manifestações contra as cotas e as políticas de permanência refletem o discurso da meritocracia, muito presente na sociedade capitalista neoliberal, que associa o mérito como causa e efeito de uma ação individual e não considera as possíveis desigualdades sociais, econômicas e culturais, facilitando, assim, a perpetuação das distorções de uma sociedade discriminatória e excludente (SILVA, 2017). O que se observou, por 
meio dos questionários, foi que uma pequena parte $(2 \%)$ desses egressos cotistas raciais reproduz o mito da democracia racial, apesar de serem frutos dos primeiros anos das políticas de reservas de vagas no Brasil.

Por fim, foi perguntado aos entrevistados que responderam "não" na resposta anterior, quais formas de melhoria da política de permanência para estudantes cotistas raciais na UEL poderiam ser implantadas. As respostas a essa pergunta foram expressas na Tabela 7.

Tabela 7 - Sugestões para melhoria das políticas de permanência da UEL.

\begin{tabular}{|l|l|l|}
\hline $\begin{array}{l}\text { Total de } \\
\text { respostas }\end{array}$ & $\begin{array}{l}\text { Em } \\
\text { \% }\end{array}$ & Sugestões \\
\hline 106 & 53 & Não respondeu \\
\hline 9 & 4,5 & $\begin{array}{l}\text { Resposta evasiva e confusa / ou que se direcionaram para o sistema de } \\
\text { cotas já existente }\end{array}$ \\
\hline 22 & 11 & $\begin{array}{l}\text { Ampliar as políticas de permanência (moradia, alimentação, transporte e } \\
\text { fotocópias/impressão) }\end{array}$ \\
\hline 17 & 8,5 & Apoio psicológico e pedagógico e psicológico \\
\hline 16 & 8 & Ampliar projetos e bolsas de pesquisa, ensino e extensão \\
\hline 5 & 2,5 & $\begin{array}{l}\text { Melhorar a formação dos/as professores/as quanto ao conhecimento das } \\
\text { cotas }\end{array}$ \\
\hline 7 & 3,5 & Rede de contato/partilha entre estudantes cotistas de diversos cursos \\
\hline 7 & 3,5 & $\begin{array}{l}\text { Ampliar a divulgação das políticas de permanência / usar meio de } \\
\text { comunicação, redes sociais }\end{array}$ \\
\hline 1 & 0,5 & $\begin{array}{l}\text { Criar mais oportunidades de pesquisas, ensino e extensão para estudantes } \\
\text { do noturno }\end{array}$ \\
\hline 3 & 1,5 & $\begin{array}{l}\text { Disciplina que discuta as desigualdades sociais e as minorias para todos os } \\
\text { cursos de graduação }\end{array}$ \\
\hline 2 & 1 & $\begin{array}{l}\text { Criar programas nas escolas das periferias que incentivem o ingresso na } \\
\text { universidade e a realização de uma carreira científica }\end{array}$ \\
\hline 1 & 0,5 & Criar uma coordenadoria de Ações Afirmativas na UEL \\
\hline 1 & 0,5 & Acesso a uma internet de qualidade \\
\hline 1 & 0,5 & $\begin{array}{l}\text { Contato com os estudantes cotistas ao ingressar, para descobrir se o mesmo } \\
\text { tem necessidade de bolsa permanência }\end{array}$ \\
\hline Criar cotas para a pós-graduação \\
\hline 1 & 0,5 & $\begin{array}{l}\text { Avaliar as condições sociais dos estudantes de cursos que necessitam de } \\
\text { materiais de alto custo, como odontologia e jornalismo }\end{array}$ \\
\hline 1 & & \\
\hline 1 & &
\end{tabular}

Fonte: Dados da pesquisa (2018).

Por meio das respostas a essa pergunta, os egressos poderiam sugerir modificações e criação de políticas de permanência que beneficiariam os graduandos oriundos do sistema de reservas de vagas. As sugestões mais recorrentes foram a de auxílio financeiro, depois o apoio pedagógico e/ou psicológico e também o aumento das bolsas de ensino, de pesquisa e de extensão.

Ressaltam-se ainda sugestões que se destacaram, como a ampliação da divulgação das políticas de permanência em meios de comunicação como TV, rádios e nas redes sociais, 
como Facebook e WhatsApp da UEL. Dois entrevistados também sugeriram um programa que visasse ao desenvolvimento de visitas à escolas das periferias, para incentivar o ingresso de jovens negros na Universidade e a realização de uma carreira científica. Essa sugestão, em específico, já vem sendo realizada por meio do PROPE, como já discutido.

Por fim, destaca-se também a sugestão de criar uma Coordenadoria de Ações Afirmativas na $\mathrm{UEL}^{3}$ com o objetivo de apoiar as atividades e as demandas que dizem respeito à temática de Ações Afirmativas nessa Universidade, iniciativa essa presente no programa de candidatura do reitor eleito em meados do ano de 2018, e que até agora não iniciou a implantação.

\section{CONSIDERAÇões FINAIS}

Por meio da aplicação e da sistematização das respostas desse questionário, foi possível compreender que as políticas de permanência implantadas na Universidade Estadual de Londrina conseguem, em parte, cumprir seu papel. No entanto, ainda há um longo caminho, com diversos desafios, para que os ingressantes no sistema de cotas raciais da UEL não sofram qualquer tipo de discriminação durante seu percurso acadêmico.

Apesar da presente pesquisa ter sido realizada com os egressos cotistas raciais e de já se ter provas de que a permanência entre eles é mais alta do que entre os estudantes que ingressaram pelo sistema universal e pelo sistema de cota social, não se deve esquecer dos estudantes que por diversas dificuldades, a exemplo das que aqui foram mencionadas, não puderam permanecer na graduação.

Frisa-se que o auxílio financeiro ainda é o maior obstáculo enfrentado por esses estudantes, mas que outros desafios também foram citados por uma significante parte deles, como a necessidade de apoio pedagógico e psicológico, a necessidade de ampliação da divulgação das Bolsas Permanência, de Iniciação Científica, e de projetos de ensino e extensão.

Contudo, considera-se que esta pesquisa se constitui apenas como ponto inicial para se compreender os impactos das políticas de permanência na UEL e os desafios encontrados pelos cotistas raciais durante seu percurso acadêmico. Dessa forma, torna-se ainda fundamental realizar estudos que proporcionem melhor entendimento sobre essa temática para que, futuramente, se façam ajustes, melhorias e ampliações quando possíveis, buscando a democratização da universidade por meio não apenas da reserva de vagas, mas também de políticas e ações práticas que visem à inserção e à permanência desses estudantes.

Ressalta-se um estudo futuro sobre os impactos que os cortes financeiros de 2019 nas políticas de ações afirmativas representarão nas universidades federais, muitas das quais tiveram um bloqueio de mais de $30 \%$ de suas verbas de custeio. Além disso, muitas pesquisas que poderiam contribuir com a discussão de questões raciais e de ações afirmativas podem ter sofrido retrocessos devido à suspensão de bolsas de mestrado e doutorado anunciadas pelo governo federal no começo de maio.

No que se refere às universidades estaduais paranaenses, o cenário também é de preocupação, uma vez que o governador Ratinho Júnior decretou, em janeiro de 2019, um

3 Várias Universidades brasileiras possuem coordenadorias de Ações Afirmativas, como UFPR, UNB, UFABC, UFRGS e UNIFESP, entre outras. 
contingenciamento de $20 \%$ dos recursos, que atingem a educação em R $\$ 1,6$ bilhão. Entre esses cortes estão gastos com ampliação, modernização e recuperação da estrutura física do campus da UEL e de seu Hospital Universitário (RAMOS, 2019).

Assim, apesar de inúmeros avanços nas últimas décadas, há indícios de que os próximos anos serão de retrocesso quanto às políticas de inclusão e permanência dos que, por séculos, foram excluídos da educação superior.

\section{REFERÊNCIAS}

ASSESSORIA DE COMUNICAÇÃO SOCIAL DA UENP. UENP aprova cotas raciais e sociais para graduação. Disponível em: $<$ https:/uenp.edu.br/noticias/item/1796-uenp-aprova-cotas-raciais-e-sociais-para-graduacao> Acesso em: 6 abr. 2019.

BOURDIEU, P. A Escola conservadora: as desigualdades frente à escola e à cultura. In: CATANI, A. (Org.); NOGUEIRA, Maria Alice (Org.). Escritos de Educação, 9. ed. Petrópolis: Vozes, 2013, p. 39-64.

BRANDÃO, J. J.; CAMPOS, M. C.; LIMA, A. M. S. Políticas de Ações Afirmativas Desafiando Relações Desiguais de Poder: Acesso/Permanência na Universidade Estadual de Londrina. Revista Geographia Opportuno Tempore, Londrina, v. 4, n. 2, p. 24-44, 2018

BRASIL. Lei $\mathrm{n}^{\circ} .10 .639,9$ de janeiro de 2003. Altera a Lei $\mathrm{n}^{\circ} .9 .394$, de 20 de dezembro de 1996, que estabelece as diretrizes e bases da educação nacional, para incluir no currículo oficial da Rede de Ensino a obrigatoriedade da temática "História e Cultura Afro-Brasileira", e dá outras providências. Diário Oficial da República Federativa do Brasil, Brasília, DF., 10 jan. 2003.

BRASIL. Decreto $n^{\circ} .6 .096$, de 24 de abril de 2007. Institui o Programa de Apoio a Planos de Reestruturação e Expansão das Universidades Federais - REUNI. Diário Oficial da União, Brasília, DF., 25 abr. 2007a.

BRASIL. Portaria Normativa $\mathrm{n}^{\circ} .39$ de 12 de dezembro de 2007. Institui o Programa Nacional de Assistência Estudantil - PNAES. Diário Oficial da União, Brasília DF., 13 dez. $2007 \mathrm{~b}$.

BRASIL. Lei ${ }^{\circ}$. 12.711, 29 de agosto de 2012. Dispõe sobre o ingresso nas universidades federais e nas instituições federais de ensino técnico de nível médio e dá outras providências. Diário Oficial da União, Brasília, DF., 30 ago. 2012.

BRASIL. Portaria Normativa no 389 de 9 de maio de 2013. Cria o Programa de Bolsa Permanência e dá outras providências. Diário Oficial da União, Brasília DF, 13 de maio de 2013. 
BRASIL. Lei nº 13.005 de 25 de agosto de 2014. Aprova o Plano Nacional de Educação PNE e dá outras providências. Diário Oficial da União, Brasília DF., 26 jun. 2014.

CARVALHO, J. J. de. Ações afirmativas para negros na pós-graduação, nas bolsas de pesquisa e nos concursos para professores universitários como resposta ao racismo acadêmico. In: SILVA, P. B. G.; SILVÉRIO, V. R. (orgs.). Educação e ações afirmativas: entre a injustiça simbólica e a injustiça econômica. Brasília: Instituto Nacional de Estudos e Pesquisas Educacionais Anísio Teixeira, 2013.

COSTA, S. L. da; DIAS, S. M. B. A permanência no ensino superior e as estratégias institucionais de enfrentamento da evasão. Curitiba, Revista Jornal de Políticas Educacionais, Curitiba, v. 9, n. 17 e 18, p. 51-60, ago./dez. 2015.

CUNHA, E. O. Implementação da Política de Permanência de Estudantes na Universidade Federal da Bahia, 2017, 213s. Tese (Doutorado em Educação) - Universidade Federal da Bahia, Salvador, 2017.

DUARTE JÚNIOR, N. G. A Assistência Estudantil e as Cotas Sociais Nas Universidades Estaduais do Nordeste: as faces do acesso ao direito, 2013, 133s. Dissertação (Mestrado em Serviço Social) - Universidade Federal do Rio Grande do Norte, 2013.

FERES JÚNIOR, J. et al. Políticas de ação afirmativa nas universidades estaduais (2016). In: Levantamento das políticas de ação afirmativa (GEMAA), IESPUERJ, p. 1-32, 2017.

FERES JÚNIOR, J.; DAFLON, V. T. Ação afirmativa na Índia e no Brasil: um estudo sobre a retórica acadêmica. Sociologias, Porto Alegre, v. 17, n. 40, p. 92-123, set./dez. 2015.

FONAPRACE - FÓRUM NACIONAL DE PRÓ-REITORES DE ASSUNTOS COMUNITÁRIOS E ESTUDANTIS. V Pesquisa Nacional do perfil do socioeconômico e cultural dos (as) Graduandos (as) das IFES- 2018. Uberlândia: Fonaprace, 2019.

GISI, M. L.; PEGORINI, D. G. As políticas de acesso e permanência na educação superior: a busca da igualdade de resultados. Revista Online de Política e Gestão Educacional, Araraquara, v. 20, n. 1, p. 21-37, jan./abr. 2016.

GOMES, J. B. O debate constitucional sobre ações afirmativas. In: SANTOS, R. E. dos; LOBATO, F. (Org.). Ação afirmativa: políticas públicas contra as desigualdades raciais. Rio de Janeiro: DP\&A, 2003, p. 15-57.

GOMES, N. L. Ações afirmativas e o desafio da permanência dos (as) jovens negros(as) na universidade pública. In: SILVÉRIO, V. R.; MOEHELECKE, S. Ações afirmativas nas políticas educacionais: o contexto pós-Durban. São Carlos: EDUFSCar, 2009. 
KENNEDY, R. O Supremo Tribunal dos Estados Unidos e a ação afirmativa: o caso do ensino superior. In: PAIVA, A. R. Ação afirmativa em questão: Brasil, Estados Unidos, África do Sul e França. Rio de Janeiro: Pallas, 2013, p. 150-208.

LEMPERT, R. Ação afirmativa nos Estados Unidos: breve síntese da jurisprudência e da pesquisa social científica. Sociologias, Porto Alegre, v. 17, n. 40, p. 34-91, set./dez. 2015.

MACHADO, E. A. Dentro da lei: as políticas de ação afirmativa nas universidades. In: PAIVA, A. R. Ação afirmativa em questão: Brasil, Estados Unidos, África do Sul e França. Rio de Janeiro: Pallas, 2013, p. 18-38.

MACIEL, C. E.; LIMA, Elizeth Gonzaga dos Santos; GIMENES, F. V. Políticas e permanência para estudantes na educação superior. Revista Brasileira de Política e Administração da Educação, Goiânia, v. 32, p. 645-929, 2016.

MEDEIROS, C. A. Ação afirmativa e promoção da igualdade: uma visão comparativa. In: SILVÉRIO, V. R.; MOEHELECKE, S. Ações afirmativas nas políticas educacionais: $\mathrm{o}$ contexto pós-Durban. São Carlos: EDUFSCar, 2009, p. 55-76.

MINISTÉRIO DA SAÚDE. BRASIL AFROATITUDE: Programa Integrado de Ações Afirmativas para Negros, 2004. Disponível em: $<$ http://bvsms.saude.gov.br/bvs/publicacoes/BRASILAFROATITUDE.pdf $>$ Acesso em: 26 mar. 2019.

OLIVEIRA, C. V. de C. Ações Afirmativas na Universidade Estadual de Feira de Santana-Uefs: Permanência das (os) Estudantes Cotistas no Ensino Superior, 2015, 184s. Dissertação. (Mestrado em Políticas Sociais e Cidadania) - Universidade Católica do Salvador, 2015.

RAMOS, M. F. Ratinho Jr. Decreta contingenciamento de $20 \%$ dos recursos do Estado, 2019. Disponível em: <https://www.folhadelondrina.com.br/politica/ratinho-jr_-decreta-contingenciamento-de-20-dos-recursos-do-estado-1024066.html>. Acesso em: 31 jul. 2019.

SANTOS, I. A. Direitos humanos e as práticas de racismo: o que faremos com os brancos racistas, 2009, 298s. Tese (Doutorado) - Universidade de Brasília, Brasília, 2009.

SILVA, M. Cotas raciais na universidade brasileira e a ideologia da meritocracia. Revista Diálogo Educacional, Curitiba, v. 17, n. 54, p. 1.207-1.221, jul./set. 2017.

SILVA, M. N. da. As cotas raciais na Universidade Estadual de Londrina e a proporcionalidade: o impacto de uma particularidade. In: SANTOS, J. T. (Org.). Cotas nas Universidades: análise dos processos de decisão. Salvador: UFBA, 2012, p. 77-98. 
SILVA, M. N. da. Uma década das ações afirmativas na UEL (2004-2014). Revista do Programa de Pós-Graduação em Sociologia da Universidade Federal de Sergipe, Aracaju, v. 1, n. 24, p. 217-236, 2014.

SILVA, P. B. Ações afirmativas para além das cotas. In: SILVÉRIO, V. R.; MOEHELECKE, S. Ações afirmativas nas políticas educacionais: o contexto pós-Durban. São Carlos: EDUFSCar, 2009, p. 264-270.

SOUZA, A. E. P. de. O engendramento de uma nova sociabilidade: as políticas de ação afirmativa e suas influências no contexto acadêmico, 2018, 172s. Tese (Doutorado em Serviço Social e Política Social) - Universidade Estadual de Londrina, Londrina, 2018.

UNIVERSIDADE ESTADUAL DE LONDRINA. Resolução CU nº $\mathbf{. 7 8} / \mathbf{2 0 0 4}$. Estabelece a reserva de vagas no Concurso Vestibular para candidatos oriundos de Instituições Públicas de Ensino e para aqueles que se autodeclararem negros. Londrina, 2004.

UNIVERSIDADE ESTADUAL DE LONDRINA. Resolução CU nº. 008/2017. Estabelece a reserva de vagas no Processo Seletivo Vestibular e no Sistema de Seleção Unificada do Ministério da Educação para candidatos oriundos de instituições públicas brasileiras de ensino e para aqueles que se autodeclararem negros. Londrina, 2017.

UNIVERSIDADE ESTADUAL DE LONDRINA (Serviço de Bem Estar à Comunidade). Edital $\mathbf{n}^{\mathbf{0}}$. 074/2018. Programa Institucional de Apoio a Inclusão Social, Pesquisa e Extensão Universitária- PIBIS 2018- Fundação Araucária. Londrina, 2018.

UNIVERSIDADE ESTADUAL DE LONDRINA (Serviço de Bem Estar à Comunidade). Edital $\mathbf{n}^{\mathbf{0}}$. 001/2019. Processo Unificado de Seleção Socioeconômica para Programas de Permanência Estudantil na UEL. Londrina, 2019.

UNIVERSIDADE ESTADUAL DE PONTA GROSSA. Resolução UNIV Nº 14 DE 9 DE DEZEMBRO DE 2013. Aprova normas relativas à realização de Concursos Vestibulares na Universidade Estadual de Ponta Grossa - UEPG, e revoga disposições em contrário. Ponta Grossa, 2013.

UNIVERSIDADE ESTADUAL DO PARANÁ. Sessão extraordinária do COU debaterá Minuta de Políticas de Cotas da Unespar, 2019. Disponível em: < http://www.unespar. edu.br/noticias/sessao-extraordinaria-do-cou-debatera-minuta-de-politica-de-cotas-da-unespar> Acesso em: 5 abr. 2019. 


\section{Dados das AUTORAS}

\section{JÉSSICA JUSTINO BRANDÃo}

Graduada em Geografia pela Universidade Estadual de Londrina. Londrina/PR-Brasil. Professora de Educação Básica do Estado do Paraná. Paraná/PR-Brasil. jessicajustino65@ gmail.com

\section{Margarida De Cássia Campos}

Doutorado em Geografia pela Universidade Federal de Santa Catarina. Santa Catarina/ SC-Brasil. Professora do curso de Licenciatura em Geografia e do curso de Especialização de Ensino de Geografia da Universidade Estadual de Londrina. Londrina/PR-Brasil mcassiacampos@hotmail.com

Submetido em: 30-12-2019

Aceito em: 19-11-2020 